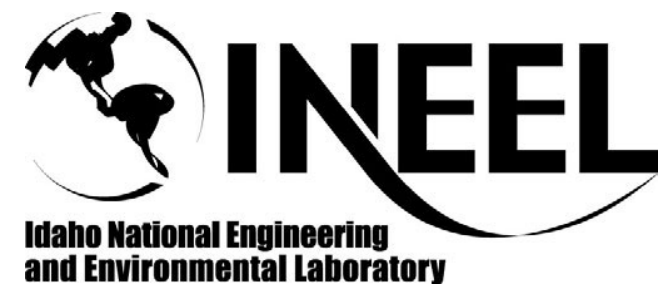

\author{
INEEL/CON-04-01906 \\ PREPRINT
}

\title{
Compressed Gas Safety For Experimental Fusion Facilities
}

\author{
L. C. Cadwallader
}

September 14-16, 2004

\section{Sixteenth Topical Meeting on the Technology of Fusion Energy}

This is a preprint of a paper intended for publication in a journal or proceedings. Since changes may be made before publication, this preprint should not be cited or reproduced without permission of the author. This document was prepared as an account of work sponsored by an agency of the United States Government. Neither the United States Government nor any agency thereof, or any of their employees, makes any warranty, expressed or implied, or assumes any legal liability or responsibility for any third party's use, or the results of such use, of any information, apparatus, product or process disclosed in this report, or represents that its use by such third party would not infringe privately owned rights. The views expressed in this paper are not necessarily those of the U.S. Government or the sponsoring agency. 


\title{
Compressed Gas Safety for Experimental Fusion Facilities
}

\author{
L. C. Cadwallader \\ Idaho National Engineering and Environmental Lab, P.O. Box 1625, Idaho Falls, ID 83415-3860; lcc@inel.gov
}

Experimental fusion facilities present a variety of hazards to the operators and staff. There are unique or specialized hazards, including magnetic fields, cryogens, radio frequency emissions, and vacuum reservoirs. There are also more general industrial hazards, such as a wide variety of electrical power, pressurized air and cooling water systems in use, there are crane and hoist loads, working at height, and handling compressed gas cylinders. This paper outlines the projectile hazard associated with compressed gas cylinders and methods of treatment to provide for compressed gas safety. This information should be of interest to personnel at both magnetic and inertial fusion experiments.

\section{INTRODUCTION}

Steel cylinders of compressed industrial gases are used at virtually all fusion experiments. Nitrogen is used as a fill gas in vacuum vessels and in gloveboxes to reduce intrusion of humid room air, hydrogen and deuterium gases are used as fuel sources, and P-10 gas ( $10 \%$ by volume methane and $90 \%$ argon) is used for a cover gas in radiation counters such as ionization chambers and portal-type contamination monitors. Sometimes halon gas or carbon dioxide gas is used as a fire suppression gas. Other gases may be used to cool diagnostic devices or as lasing gases for laser diagnostics; choices include carbon dioxide, neon, argon, and others. A typical $140 \mathrm{~cm}$ tall by $23 \mathrm{~cm}$ diameter gas cylinder from a gas supply company is pressurized to $\sim 13 \mathrm{MPa}$ $(2,000 \mathrm{psia})$ and weighs about $62 \mathrm{~kg}$ (136 pounds). In the press of experiment activity, proper treatment of gas cylinders can be overlooked. Cylinders might be secured well to sturdy structural members, they may be tied with a piece of binder twine, or they may be left free standing. The reasons for compressed gas safety, some recent events involving gas cylinders and compressed gas, and suggested methods for treating gases are discussed in this paper.

\section{COMPRESSED GAS HAZARDS}

There are a number of hazards with compressed gas use and handling. Some are obvious and some are not.
Lees ${ }^{1}$ described some of these hazards. The most frequent hazard is misidentification of the gas in the cylinder, leading to introduction of a gas that is not appropriate for the application. Gas cylinders are often color-coded or tag labeled, but the paint or label can rub off, or be mistaken, or be misunderstood. Cylinders can be overfilled, either by faults in the filling machinery or by human error. Another hazard is that the cylinder isolation valve, usually brass, can be easily damaged. If the valve is damaged badly, it can allow gas to directly flow from the cylinder, in which case the cylinder can become a projectile propelled by escaping gas. There are other hazards as well. Gas cylinders tend to be heavy, and are sometimes dropped when being handled. A $62 \mathrm{~kg}$ item can damage a diagnostic device, a vacuum pump line, etc., if it topples over or is dropped. Toppling cylinders have pinched workers' hands, some events resulting in broken bones and amputated fingers, as seen in the Department of Energy's Computerized Accident/Incident Reporting System (DOE CAIRS). CAIRS also has dozens of reports, over twenty years, regarding broken teeth, broken mandibles, and facial lacerations resulting from workers trying to pick up gas cylinders by the cap; cap failures are usually from insufficient threads engaged, worn threads, or a cracked cap wall. Another hazard is gas leakage that can displace the air in the room; hence oxygen monitors or toxic gas monitors are often installed for personnel protection in gas storage areas. If a gas is flammable, then leakage poses the additional hazard of fire or explosion.

Asfahl $^{2}$ noted the projectile hazard and gave this description: "It is difficult to comprehend the energy that can be released by the sudden rupture of the valve on an oxygen cylinder containing $13 \mathrm{MPa}$ pressure .... consider the hazard of a heavy cylinder flying wildly around the room like a rapidly deflating balloon." Asfahl makes a compelling case about the non-obvious hazard of stored pressure energy. The scenario seems improbable, but an operating experience review indicates that the events are not as rare as we would hope and that a few of these runaway cylinder events have occurred within the US DOE complex in the last 14 years. 
Guymon $^{3}$ stated that gas cylinder projectiles can damage safety instrumentation or electrical lines, break small pipe lines, damage valve operators or other appendages of large pipe lines, and pumps, valves or other equipment could be made inoperable from impact with a gas cylinder missile. In addition, personnel could be injured or killed.

\section{COMPRESSED GAS CYLINDER PROJECTILES}

Guymon $^{3}$ described a few gas cylinder projectile incidents. A noteworthy event occurred when a technician was removing a halon 1211 cylinder as part of a system decommissioning task. The technician either caught his sleeve on the manual actuation lever, or his forearm brushed the lever. The cylinder began to release its $4 \mathrm{MPa}$ (600 psi) nitrogen cover gas and the pressureliquefied halon gas. The cylinder began bouncing along the floor, where it lost its isolation valve. At that point, the cylinder became airborne and traveled upward. It struck a roof access platform and ricocheted, penetrating two sheet metal walls to enter an adjacent building. The cylinder angled upward again and penetrated the sheet metal roof of the second building. The cylinder rose up to about $43 \mathrm{~m}$ (140 feet); it fell back to earth after its gas was expended. In its fall, the cylinder again penetrated the sheet metal roof at about $40 \mathrm{~m}$ from where it had first released gas.

Another event involving halon was described by the US Nuclear Regulatory Commission. ${ }^{4}$ Two technicians were performing a biennial surveillance on the plant's halon gas cylinders. The cylinders, which were nominally $1 \mathrm{~m}$ long and $0.4 \mathrm{~m}$ in diameter, were pressurized to $2.4 \mathrm{MPa}$ with $86 \mathrm{~kg}$ of Halon and weighed about $159 \mathrm{~kg}$ (350 pounds) when fully charged. The technicians removed a cylinder to weigh it; this task is part of periodic test surveillance, weighing determines if the cylinder has retained its correct halon inventory. To weigh the cylinder, the technicians moved the cylinder to a shower/restroom area where scales were kept. A technician removed fittings, as per procedures, so they would not be weighed. He inadvertently removed a valve fitting that allowed the cylinder to vent. The cylinder began moving, and the two technicians were injured, one seriously, as a result of impacts. Extensive damage was also caused in the shower and restroom; gouges were made in the tile of a shower wall and a $5-\mathrm{cm}$ deep gouge was made in the concrete floor. Then the halon cylinder penetrated a 0.15 -m thick cinder block wall, leaving an opening approximately $0.1 \mathrm{~m}^{2}$.

Failure Analysis Associates ${ }^{5}$ investigated the failure of a self contained breathing apparatus (SCBA) cylinder in 1996. The $30 \mathrm{MPa}(4,500 \mathrm{psig})$ cylinder was an aluminum inner liner with a fiberglass composite outer wrapping; its volume was $0.009 \mathrm{~m}^{3}$. The fiberglass suffered stress corrosion cracking initiated by an inadvertent chemical exposure to a metal cleaning solvent. Without the fiberglass composite support, the liner could not withstand the pressure. The SCBA catastrophically failed several days after the chemical exposure. The cylinder was stored in a compartment on the side of a fire engine; the compartment steel door was forced from its hinges and badly deformed in this pressure explosion, and an adjacent compartment door was also blown open and slightly deformed. The flying debris also damaged the other fire engine parked next to compartment. No personnel were nearby at the time of the failure; no one was injured.

The Center for Chemical Process Safety ${ }^{6}$ described a recent fire suppression system event involving a tank of "FM-200" gas (heptafluoropropane gas, typical storage pressure is $2.5 \mathrm{MPa}$ ) at an industrial facility. An operator was removing two cylinders from service, and one cylinder valve was accidentally tripped open. The cylinder launched itself upward and penetrated the sheet metal roof of the building. It expended its gas and fell back onto the roof. A similar event with a halon gas cylinder occurred at an accelerator facility in $2002{ }^{7}$

The National Institute for Occupational Safety and Health published some safety guidance on gas cylinders. ${ }^{8}$ An event from the 1960's was described where six carbon dioxide fire suppressant cylinders had been moved to allow wall painting. Upon reinstallation, a cylinder valve separated (due to past damage) while a painter was moving the cylinder back into position. The moving cylinder knocked another painter from a scaffold, caromed off walls, and made its way into a nearby truck well where it expended its remaining pressure energy by spinning and impacting the concrete walls.

The US DOE Occurrence Reporting and Processing System (ORPS) (located at http://tis.eh.doe.gov) has several gas cylinder reports pertinent to this discussion, as well other reports of pinhole leaks through cylinder walls, leaking valves, wrong gases plumbed to a system, radiological contamination on cylinders, wrong pressures applied, wrong markings on cylinders, cylinder missed hydrostatic tests, etc. The compressed gas events that resulted in missiles are described briefly in Table I.

The operating experiences from Table I illustrate that there have been only a few reported compressed gas cylinder leaks and "missiles" in the past $~ 14$ years of DOE ORPS reporting. Considering the scope of operations by the $\sim 130,000$ employees in the 24 national laboratories and technology centers across the DOE complex, the frequency gas cylinder problems is low. None of the events described in Table I resulted in a 
Near Miss - Pressurized Respirator Bottle Unexpectedly Discharges Causing Minor Injuries

On April 20, 2004, a technician was performing a routine bottle changing operation. As he was tightening a regulator and hose to a fresh respirator bottle, the bottle valve was ejected by the $20 \mathrm{MPa}$ bottle pressure. The valve and regulator impacted a room wall and penetrated two dry wall surfaces to enter the next room, where it ricocheted from a metal shelf and fell back into the original room. The bottle accelerated and struck the technician on the upper thigh, moving him back several feet, then its gas was expended. The technician experienced contusions to the leg and hip, a second individual was knocked over, the technician and other personnel in the room were exposed to the loud noise of the bottle valve failure. Examination showed material damage to both the bottle and the valve threads; the cause could not be determined. The torque to tighten the regulator caused the damaged threads to give way, launching the bottle and the valve.

Compressed Gas (Argon) Bottle Falls Breaking Regulator-almost a runaway cylinder

On March 8, 2000, a subcontractor sheet metal worker was re-positioning welding leads/argon hose for a welding activity. As the worker pulled and moved the leads, the connected argon cylinder (compressed gas) fell over out of its containment cart and landed on the floor. When the cylinder struck the floor, the stem connection from the regulator was broken and separated from the cylinder. The cylinder was at approximately 5.4 MPa; the argon gas began escaping vertically from the cylinder nozzle. A nearby safety representative witnessed the event, hesitated a few seconds to determine that the cylinder was not going to move, then approached the cylinder and closed the cylinder valve. There were no injuries to personnel or damage to property as a result of this incident.

Two Firefighters Injured while Discharging $\mathrm{CO}_{2}$ Cylinder

On December 8, 1998, in preparation for hydro testing of a $\mathrm{CO}_{2}$ cylinder, a firefighter inadvertently actuated the trigger mechanism on a $\mathrm{CO}_{2}$ cylinder. This action caused the $5.4 \mathrm{MPa} \mathrm{CO}_{2}$ cylinder to discharge, propelling it from a cart the workers had used to transport it to a parking area. The cylinder spun out of control in the parking lot and struck one of the fire fighters in the calf, causing a laceration. The other firefighter fell as he was evading the cylinder; he received elbow and knee abrasions. One firefighter was transported to the hospital and the other was treated at the site clinic. The cylinder did not cause any other damage. The CAIRS report on this event indicated that the hospitalized firefighter had complications from the laceration; there was a significant amount of lost work time ( $>0.3$ year) to properly heal.

Accident resulting in minor injury to an employee (near miss) almost a runaway cylinder

On June 18, 1996, two employees were assigned to perform piping pressure tests. The task required moving a $13 \mathrm{MPa}$ nitrogen gas cylinder to the test location. They carted the cylinder, with cap attached, to a stairwell. They uncarted the cylinder and began to slide it down the stairs; one employee was above and one was below. They lost control of the cylinder; it struck one employee as it slid down the stairway, he fell about 3-4 steps to the landing. The cylinder rolled about 14 or 16 steps and stopped on the landing; the cap had been dislodged and the valve stem was sheared at the packing nut. No nitrogen escaped, but this was a near miss as a valve loss accident. The cylinder was removed to the outdoors, vented and discarded.

\section{Near Miss - Carbon Dioxide Cylinder Incident}

On September 20, 1995, a $45.5 \mathrm{~kg} \mathrm{CO}_{2}$ compressed gas cylinder (estimated to be $5.7 \mathrm{MPa}$ ) escaped its storage location at the north side of a lab building following an uncontrolled release of $\mathrm{CO}_{2}$. Two Fire Department (FD) workers narrowly escaped injury when the cylinder exited the storage enclosure. The workers were conducting a task pre-planning evolution for the removal of all $\mathrm{CO}_{2}$ compressed gas cylinders from the cylinder storage area of an obsolete, fixed fire protection system. No other personnel were in the area when the cylinder propelled itself out of the storage enclosure, striking a paved parking area and spinning out of control. After striking the ground the cylinder traveled about $9 \mathrm{~m}$ (30 feet) and struck an inclined concrete ramp, which restricted further movement. The cylinder came to rest following the release of its contents. The FD workers stated they intended to examine the use of a hand lever attachment, which is connected to the valve assembly, as a means of discharging the cylinder contents. A general lack of knowledge regarding cylinder discharge valve design and intent, coupled with the failure to recognize that the cylinder was improperly restrained, initiated this event.

\section{Damage to Unsecured Gas Cylinder-almost a runaway cylinder}

On December 5, 1990, a subcontractor electrician had removed a $13 \mathrm{MPa}$ argon gas cylinder from a welding cart to gain access to the cart's electrical panel. The cart rolled down a slight incline, putting tension on the gas hose that was still connected to the argon cylinder. The cylinder was pulled over. The regulator stem was broken off in the fall, but no gas escaped from the cylinder. There were no injuries although an employee was only $\sim 1.5 \mathrm{~m}$ away from the falling cylinder. 
process gas (e.g., nitrogen, P-10, argon, helium, etc.) having a valve loss and becoming a missile inside a facility. There were; however, three reports of 'near miss' missile events involving two argon cylinders and one nitrogen cylinder. There was also one event of a SCBA respirator cylinder becoming a missile. There were two carbon dioxide suppression gas events that led to cylinder missiles. Qualitatively, the gas cylinder missile events seem to be rare, but nonetheless three events and three near misses have occurred within the 14-year time span of the ORPS database. An initial estimate of the occurrence frequency of a gas cylinder missile at an individual DOE lab or research complex would be an unlikely event (1E-02 to $1 \mathrm{E}-04 /$ year). While gas cylinder 'missile' events may be rare, the consequences can be severe. It is positive that there have not been any gas cylinder events reported at fusion facilities; however, not all events may be reaching the database.

\section{COMPRESSED GAS SAFETY}

The main issue in gas cylinder safety is to treat the gas cylinders with respect, remembering what sort of damage a mistreated cylinder can create. The following section shows how much thrust and what velocity can be reached with these cylinders. Another issue is proper cylinder restraint. At some fusion experiments, simple cords or twine have been used to secure cylinders. While the gas cylinder regulations (29CFR1910.101) and Compressed Gas Association guidance ${ }^{9}$ do not state what type of restraint to use, the construction safety regulations (29CFR1926.350) do state that a cylinder truck or chains should be used to prevent cylinders from falling over. There are several reasons for using chains. If a cylinder were to begin to whirl around on its axis due to a leak, a chain will continue to confine the cylinder well. If a rope or cord begins to bind on a whirling cylinder, the force may part the restraint and allow the cylinder to fall over. Metal chain is also typically much stronger than stranded rope or cord. Chains wear better than rope, and a hook connection with a chain is always the same, which is not uniformly true of worker knot tying proficiency with twine, rope, or cord. In a fire situation, typically under $1,000^{\circ} \mathrm{C}$, steel chains retain a fair amount of their yield strength; if the pressure relief fusible link on the gas cylinder opens in the fire then the cylinder needs to be well-restrained so it does not fall over and move, which could easily add more damage and potentially spread the fire already in progress. The pressure relief fusible link is designed to direct escaping gas in four directions, each $90^{\circ}$ from the other, so that there is no net thrust in any direction. If there is pressure relief nozzle fouling, or partial link melting, then there will be unbalanced thrust that can cause the cylinder to whirl or tip over. Another issue to consider is that the rope or cord can burn or melt in a fire, leaving the cylinder freestanding as it is being overheated. There is no rule on what type of chain to use, and the entire range of flimsy (decorative or pet-walking chain) to robust (vehicle towing chain) has been seen in use in various facilities. Safety guidance is to select a chain that will restrain the cylinder in an earthquake situation; ${ }^{10}$ thus, an obviously lightweight chain will not provide adequate restraint. Chen ${ }^{10}$ stated that 100 gas cylinders, improperly restrained, failed during the 6.6 Richter magnitude Northridge earthquake near Los Angeles, California in January 1994. These cylinders added their gas release to the other chemical releases from broken chemical containers in laboratories and businesses.

One of the primary ways to preserve gas cylinders is to keep the cylinder interior free of moisture; the presence of moisture leads to corrosion of the internal walls. Gas companies wish to use cylinders as long as possible and take steps to remove moisture when filling the cylinders. When the users also keep moisture out of the cylinders, the cylinders should have long service lives. At the author's site, there are some gas cylinders that have been in service over 60 years, having passed their periodic hydrostatic pressure tests. However, these cylinders tend to be rather thick-walled and heavier than more modern cylinders. A typical lifetime for a modern steel cylinder is $25-30$ years, less if the gas is highly corrosive, possibly longer if the cylinder is well kept. Another safety issue is to keep the cylinder exterior clean and properly painted, thus avoiding external corrosion and promoting the color-coding that allows recognition of cylinder contents. Keeping the protective steel cap on the gas cylinder when it is not in use protects the brass cylinder valve, which is the weakest part of the entire structure.

Another often-discussed safety issue is the use of a flow-restricting orifice. Gas supply companies are reluctant to include such orifices for several reasons: cost to retrofit thousands of cylinders for a low frequency accident event, the fact that some customers do not wish to use orifices, and the increase in the time needed to refill an 'orificed' cylinder could result in the company being uneconomic. Some companies have an orifice available if a customer requests it. Users can also install an orifice after the cylinder valve, as suggested by Bolman. ${ }^{11}$ The best way to protect the gas cylinder is to secure it well against any inadvertent motion and keep the cylinder isolation valve capped whenever possible so that it is not susceptible to damage.

Another safety issue germane to fusion experiments is that most gas cylinders are made of ferromagnetic steel. There have been incidents with small gas cylinders in the magnetic resonance imaging (MRI) community, ${ }^{12,13}$ some of which have led to fatalities of 
patients who were struck by gas cylinders drawn to the MRI magnet. The sets of magnets in fusion should generate less fringe field than a single MRI magnet, but fusion experiments have suffered from other magnetic field-induced projectiles. While the $62 \mathrm{~kg}$ weight of industrial gas cylinders precludes them from being drawn by a magnetic field, the cylinders should be positioned out of the fringe field and secured against any toppling that might result from motion induced by ramping magnetic fields.

\section{RUNAWAY CYLINDER CALCULATION}

As already stated, a fusion experiment may have several kinds of gas cylinders in use. A safety calculation has been performed for a $140 \mathrm{~cm}$ tall by $23 \mathrm{~cm}$ diameter, $62 \mathrm{~kg}$ empty, $0.05 \mathrm{~m}^{3}$, pressurized gas cylinder at room temperature that has had its isolation valve sheared off at the cylinder head. Guymon $^{3}$ has stated the energy release equation for an isentropic gas release:

$$
U=\frac{P_{1} V_{1}}{\gamma-1}\left\lfloor 1-\left(P_{2} / P_{1}\right)^{(\gamma-1) / \gamma}\right\rfloor
$$

where:

$\mathrm{U}$ is the total gas energy released in reversible, adiabatic expansion

$\mathrm{P}_{1}$ is the initial gas pressure in the cylinder

$\mathrm{P}_{2}$ is the final gas pressure, i.e., atmospheric pressure

$\mathrm{V}_{1}$ is the volume of the gas cylinder

$\gamma$ is the ratio of specific heats for the gas

Lees ${ }^{1}$ suggested that $91.5 \mathrm{~m} / \mathrm{s}$ is a practical upper limit for the attainable velocity of a typical gas cylinder being propelled by its own escaping gas, this value apparently was determined from a rocket thrust force equation, such as given in reference 14, assuming sonic velocity choked flow in the sheared valve. Solving for the energy release and assuming all the energy is converted into kinetic energy gives a bounding velocity term for a cylinder, always less than $91.5 \mathrm{~m} / \mathrm{s}$. Since the gas can fan out after leaving the valve, and most likely becomes supersonic flow, Lees' approach can underestimate the velocity. Table II gives some gas property values and Table III gives calculation results for gases often used in fusion facilities. The thrust to weight ratios given in Table III vary between 1.3 and 17; any value over 1.0 indicates the cylinder can move upward against the force of gravity. In fact, Atlas, Titan, and Delta launch vehicles $^{15}$ have launch pad thrust to weight ratios of 1.2 to 2 .

The velocities reported in Table III are upper bounds, since no friction losses from the gas or from the cylinder have been accounted for, and no cylinder collisions that would transfer the cylinder's energy to another object have been assumed. Considering that the mass involved is $62 \mathrm{~kg}$, the velocities in Table III are ample to cause damage to electronics cabinets, diagnostics, small diameter vacuum or water piping, ceramic breaks in piping, electrical panels, or other sensitive equipment in a fusion facility.

\section{CONCLUSIONS}

There have been several reported events of gas cylinder projectiles at industrial facilities and power station in the recent past. In the DOE complex there have been two reported runaway gas cylinder events, one SCBA event, and several near miss events in the past 14 years. Runaway or cylinder "missile" events in the US DOE are unlikely events in the $1 \mathrm{E}-02$ to $1 \mathrm{E}-04 /$ year frequency range per site. Enough events have occurred that continued diligence with gas cylinders is necessary. The event reports have shown that handling of fire suppressant gas and welding gas containers is sometimes performed by workers who are not well trained in handling these gas containers. This lack of knowledge has led to a few 'missile' events. The recorded data show that handling of process gases (nitrogen, argon, helium, etc.) has resulted in fewer accidents than handling of the welding and fire suppressant gases. There have not been any reported incidents of gas cylinder runaway events at fusion facilities, but continued diligence is prudent given the potential consequences. The energy release calculations in this paper show that there is considerable stored pressure energy that should be respected in each cylinder, and the operating experience shows the mechanical damage resulting from venting these cylinders to air, regardless of any toxic or flammable nature of the compressed gas. The safety practices at all facilities using compressed gases could be improved by remembering the stored pressure energy and the weight of these cylinders. Proper care in the use and handling of compressed gas cylinders will promote safe operations at all fusion experiments.

\section{ACKNOWLEDGMENTS}

This work was prepared for the US Department of Energy (DOE), Office of Fusion Energy Sciences, under the DOE Idaho Operations Office contract number DEAC07-99ID13727.

\section{REFERENCES}

1. F. P. LEES, Loss Prevention in the Process Industries, second edition, Butterworth Heinemann, London, volumes 2 and 3 (1996).

2. C. R. ASFAHL, Industrial Safety and Health Management, fifth edition, Pearson-Prentice Hall, Upper Saddle River, New Jersey 376 (2004). 
TABLE II. Gas Properties for Selected Fusion Gases

\begin{tabular}{|l|l|l|l|l|l|}
\hline & $\begin{array}{l}\text { Gas } \\
\text { molecular } \\
\text { weight } \\
\text { (g/mole) }\end{array}$ & $\begin{array}{l}\text { Initial gas } \\
\text { pressure } \\
\text { in cylinder } \\
\mathbf{M}\end{array}$ & $\begin{array}{l}\text { Specific } \\
\text { heat } \\
\text { ratio of gas } \\
\text { (unitless) }\end{array}$ & $\begin{array}{l}\text { Specific gas } \\
\text { constant } \\
(\mathbf{J} / \mathbf{k g}-\mathbf{K})\end{array}$ & $\begin{array}{l}\text { Sonic } \\
\text { velocity in gas } \\
\text { at 298 K } \\
(\mathbf{m} / \mathbf{s})\end{array}$ \\
\hline Argon & 39.94 & 13.6 & 1.658 & 208.15 & 320.7 \\
\hline Carbon dioxide & 44.01 & 13.6 & 1.288 & 188.92 & 269.3 \\
\hline Helium & 4.00 & 13.6 & 1.659 & 2078.2 & 1013.6 \\
\hline Hydrogen & 2.01 & 13.6 & 1.405 & 4124.2 & 1314.1 \\
\hline Neon & 20.18 & 13.6 & 1.65 & 412.0 & 450.1 \\
\hline Nitrogen & 28.01 & 13.6 & 1.40 & 296.80 & 351.9 \\
\hline P-10 & 37.55 & 13.6 & $\sim 1.6$ & 221.42 & 324.9 \\
\hline Freon-12 & 120.91 & 0.68 & 1.13 & 68.76 & 152.2 \\
\hline Halon 1301 & 148.9 & 4.1 & 1.14 & 55.84 & 137.7 \\
\hline
\end{tabular}

TABLE III. Calculated Values for Selected Fusion Gases

\begin{tabular}{|l|l|l|l|l|l|l|}
\hline & $\begin{array}{l}\text { Estimated } \\
\text { time to } \\
\text { expel gas } \\
\text { (s) }\end{array}$ & $\begin{array}{l}\text { Gas } \\
\text { Gas density } \\
\text { at pressure } \\
\left(\mathbf{k g} / \mathbf{m}^{\mathbf{3}}\right)\end{array}$ & $\begin{array}{l}\text { Mass of } \\
\text { gas in 62 kg } \\
\text { cylinder } \\
\mathbf{( k g )}\end{array}$ & $\begin{array}{l}\text { Gas } \\
\text { energy } \\
\text { release } \\
\text { (MJ) }\end{array}$ & $\begin{array}{l}\text { Maximum } \\
\text { cylinder } \\
\text { velocity } \\
\text { (m/s) }\end{array}$ & $\begin{array}{l}\text { Thrust to } \\
\text { weight ratio } \\
\text { (unitless) }\end{array}$ \\
\hline Argon & 4.9 & 219.3 & 11 & 0.885 & 155 & 3.2 \\
\hline Carbon dioxide & 5.8 & 12.1 & 0.6 & 1.57 & 224 & 3.9 \\
\hline Helium & 1.6 & 22.0 & 1.1 & 0.884 & 167 & 10.7 \\
\hline Hydrogen & 1.2 & 11.1 & 0.56 & 1.27 & 202 & 17.1 \\
\hline Neon & 3.5 & 110.8 & 5.54 & 0.894 & 163 & 4.7 \\
\hline Nitrogen & 4.1 & 153.8 & 7.7 & 1.28 & 192 & 4.8 \\
\hline P-10 & 4.9 & 206.1 & 10.3 & 0.953 & 162 & 3.4 \\
\hline Freon-12 & 1.1 & 33.2 & 1.7 & 0.051 & 69 & 6.4 \\
\hline Halon 1301 & 12.9 & 243.6 & 12.2 & 0.535 & 159 & 1.3 \\
\hline
\end{tabular}

3. R. H. GUYMON, R. CASTO, and E. L. COMPERE, Safety Implications Associated with In-Plant Pressurized Gas Storage and Distribution Systems in Nuclear Power Plants, NUREG/CR-3351, US Nuclear Regulatory Commission, Washington, DC (May 1985).

4. Compressed Gas Cylinder Missile Hazards, Information Notice 91-37, US Nuclear Regulatory Commission, Washington, DC (June 10, 1991).

5. R. S. FRANKLE and H. F. WACHOB, Investigation of the Failure of an SCBA Cylinder, FaAA-SF-R-96-06-16, Failure Analysis Associates, Inc., Menlo Park, California (July 2, 1996).

6. "The cylinder that got away," Process Safety Beacon, Center for Chemical Process Safety, American Institute of Chemical Engineers, New York (April 2002).

7. Pressurized Gas Cylinders, Danger!, CERN Safety Bulletin, TIS 2002-02 (May 2002).

8. G. A. ALLCOTT, Safety Information Profile: Compressed Gas Cylinders Charging and Handling, PB84-154186, National Institute for Occupational Safety and Health, Morgantown, West Virginia (1979).

9. Safe Handling of Compressed Gases in Containers, CGA-P-1, Compressed Gas Association (2000).
10. W.-F. CHEN and C. SCAWTHORN, Earthquake Engineering Handbook, CRC Press, Boca Raton, Florida, Chapter 30 (2002).

11. R. A. BOLMAN, Jr., Semiconductor Safety Handbook, safety and health in the semiconductor industry, Noyes Publications, Westwood, New Jersey, part 7, section 5.1 (1998).

12. G. CHALJUB, L. A. KRAMER, R. F. JOHNSON, $3^{\text {rd }}$, R. F. JOHNSON, Jr., H. SINGH, W. N. CROW, "Projectile cylinder accidents resulting from the presence of ferromagnetic nitrous oxide or oxygen tanks in the MR suite," American Journal of Roentgenology, 177, 27 (2001).

13. P. M. COLLETTI, "Size "H" oxygen cylinder: accidental MR projectile at 1.5 Tesla," Journal of Magnetic Resonance Imaging, 19, 141 (2004).

14. R. D. ARCHER and M. SAARLAS, Introduction to Aerospace Propulsion, Prentice Hall, Upper Saddle River, New Jersey 50 (1996).

15. G. P. SUTTON, Rocket Propulsion Elements, sixth edition, John Wiley \& Sons, New York, chapter 1 (1992). 